\title{
Observations and Large-Eddy Simulations of Entrainment in the Sheared Sahelian Boundary Layer
}

\author{
Guylaine Canut · Fleur Couvreux • Marie Lothon • \\ David Pino - Frédérique Saïd
}

\begin{abstract}
At the top of the planetary boundary layer, the entrainment of air, which incorporates dry and warm air from the free troposphere into the boundary layer, is a key process for exchanges with the free troposphere since it controls the growth of the boundary layer. Here, we focus on the semi-arid boundary layer where the entrainment process is analyzed using aircraft observations collected during the African Monsoon Multidisciplinary Analysis experiment and large-eddy simulations. The role of the entrainment is specifically enhanced in this region where very large gradients at the planetary boundary-layer top can be found due to the presence of the moist, cold monsoon flow on which the dry, warm Harmattan flow is superimposed. A first large-eddy simulation is designed based on aircraft observations of 5 June 2006 during the transition period between dry conditions and the active monsoon phase. The simulation reproduces the boundary-layer development and dynamics observed on this day. From this specific case, sensitivity tests are carried out to cover a range of conditions observed during seven other flights made in the same transition period in order to describe the entrainment processes in detail. The combination of large-eddy simulations and observations
\end{abstract}

G. Canut $(\bowtie) \cdot$ M. Lothon · F. Saïd

Laboratoire d'Aérologie, Université de Toulouse, CNRS UMR 5560, Toulouse, France

e-mail: guylaine.canut@aero.obs-mip.fr

M. Lothon

e-mail: marie.lothon@aero.obs-mip.fr

F. Saïd

e-mail: frederique.said@aero.obs-mip.fr

F. Couvreux

CNRM-GAME, Météo-France and CNRS, Toulouse, France

e-mail: Fleur.Couvreux@meteo.fr

D. Pino

Applied Physics Department, BarceloneTech (UPC) and

Institute for Space Studies of Catalonia (IEEC-UPC), Barcelona, Spain

e-mail: david@fa.upc.edu 
allows us to test the parametrization of entrainment in a mixed-layer model with zero-order and first-order approximations for the entrainment zone. The latter representation of the entrainment zone gives a better fit with the conditions encountered in the Sahelian boundary layer during the transition period because large entrainment thicknesses are observed. The sensitivity study also provides an opportunity to highlight the contribution of shear stress and scalar jumps at the top of the boundary layer in the entrainment process, and to test a relevant parametrization published in the recent literature for a mixed-layer model.

Keywords Entrainment · Large-eddy simulation · Sahelian boundary layer ·

Sheared boundary layer

\section{Introduction}

The entrainment of warm and dry air from the atmosphere is a key process in the convective boundary layer. The growth of the convective boundary layer (CBL) is driven both by surface fluxes of heat and moisture and by the entrainment of warm and dry air from the free atmosphere into the boundary layer. Wind shear at the surface and at the inversion layer enhances these processes, as shown by Conzemius and Fedorovich (2006a). Buoyancy and shear can substantially affect the depth of the mixed layer, the main characteristics of the CBL, and the turbulence statistics. The fundamental physical processes governing entrainment, however, and their relationship to other CBL properties remain poorly understood. The treatment of entrainment is generally oversimplified (Angevine 2008) and poorly represented in numerical models of the atmosphere (Fedorovich et al. 2004).

The most basic approach, first proposed by Lilly (1968), represents the entrainment zone as a sharp discontinuous inversion [the inversion depth, $\delta$, being equal to zero (Fig. 1)]. This representation is referred to as a zero-order jump model (ZOM). From the 1970s onwards, and with different degrees of complexity, this approach has been widely applied to study the CBL over land (e.g. Tennekes 1973, Stull 1976), the stratocumulus-topped boundary layer (Faloona et al. 2005), the formation of a coastal internal boundary layer (Gryning and Batcharova 1990), the marine boundary layer, and the impact of boundary-layer dynamics on the carbon dioxide concentration or on the atmospheric chemistry in the CBL (Kawa and Pearson 1989). The use of large-eddy simulation (LES) models has revealed that the ZOM approach is often insufficient to reproduce real conditions (Van Zanten et al. 1999) and the interface layer can be described in a more realistic way by the so-called first-order jump model (FOM). The entrainment region is then assumed to have a finite thickness $(\delta>0)$ (Fig. 1).

The simulation of boundary-layer processes by a mixed-layer model leads to a number of unknowns variables that is larger than the number of available equations (Stull 1988). To close the equations, it is assumed that the entrainment buoyancy flux is a fraction of the surface buoyancy flux, such that:

$$
\left.\overline{w^{\prime} \theta_{\mathrm{v}}^{\prime}}\right|_{i}=-\left.\beta \overline{w^{\prime} \theta_{\mathrm{v}}^{\prime}}\right|_{0}
$$

where $\left.\overline{w^{\prime} \theta_{\mathrm{v}}^{\prime}}\right|_{i}$ and $\left.\overline{w^{\prime} \theta_{\mathrm{v}}^{\prime}}\right|_{0}$ are the buoyancy flux values at the CBL top and at the surface respectively (primes denote fluctuations, $w$ is the vertical velocity and $\theta_{\mathrm{v}}$ is the virtual potential temperature); $\beta$ is the so-called 'entrainment rate'. Many studies (Tennekes and Driedonks 1981; Driedonks 1982; Pino et al. 2003) have shown that $\beta=0.2$ provides satisfactory results when shear-generated turbulence is negligible. Other numerical simulations and 


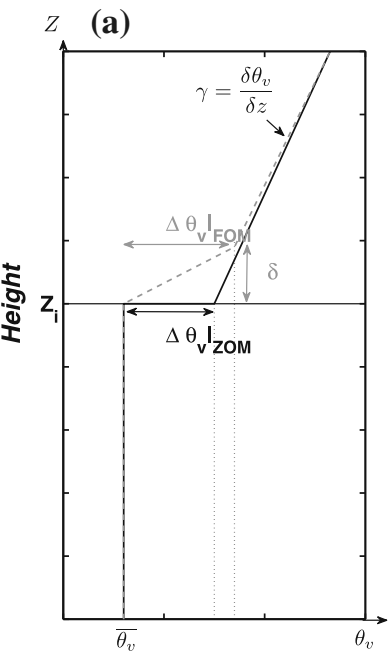

$z$ (b)

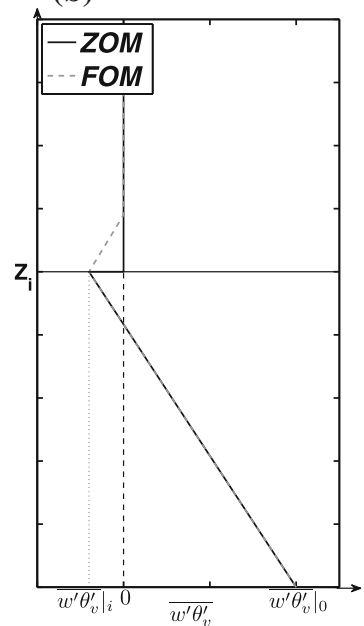

$Z$ (c)

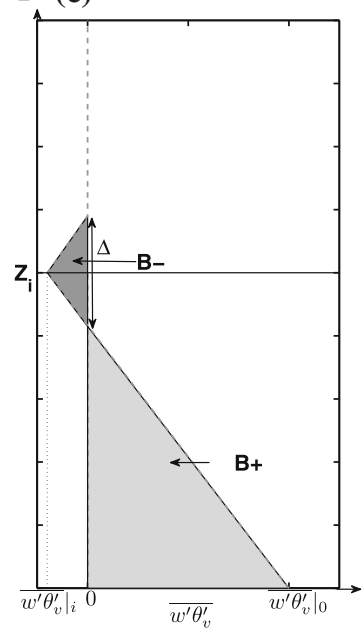

Fig. 1 Schematic profiles of a the virtual potential temperature $\theta_{\mathrm{V}}$ and $\mathbf{b}$, $\mathbf{c}$ the buoyancy flux $\overline{w^{\prime} \theta_{\mathrm{V}}^{\prime}}$ assuming (solid black) a zero-order jump model (ZOM) and (dashed grey) a FOM. $Z_{i}$ is the boundary-layer top. $\left.\Delta \theta_{\mathrm{V}}\right|_{\text {ZOM }}$ and $\left.\Delta \theta_{\mathrm{V}}\right|_{\mathrm{FOM}}$ are the virtual potential temperature jump between the free troposphere and the boundary layer. $\delta$ is the depth of the entrainment zone and $\gamma$ is the gradient of virtual potential temperature in the free troposphere. $\mathbf{c}$ The change in sign of the buoyancy flux defines two areas, $B-$ and $B+$, obtained by integrating the buoyancy flux over height and $\Delta$ is the thickness of the negative area

observations (Sorbjan 1996; Sullivan et al. 1998; Van Zanten et al. 1999; Kim et al. 2003; Pino et al. 2006; Conzemius and Fedorovich 2006a,b; Sun and Yuan 2008) have found that $\beta$ can vary between 0.1 and 0.4 according to the level and magnitude of the wind shear and the strength of the inversion. The same studies underline the importance of considering not only $\beta$ but also the structure of the inversion layer, in order to properly represent the dynamics of the $\mathrm{CBL}$ and the entrainment processes.

Our study is devoted to the entrainment in an environment characterized by two different flows: the south-westerly moist, cool monsoon flow topped by the north-easterly dry, warm Harmattan flow into the Saharan air layer (SAL). During the so-called pre-onset period from May to July, between dry conditions and the active monsoon phase, the planetary boundary layer (PBL) grows within the monsoon flow and rapidly reaches the bottom of the SAL (see Canut et al. 2010) due to strong surface heating, leading to large wind shear and thermodynamical differences at the PBL top. The objectives of the study are, (i) to understand the entrainment processes in a sheared boundary layer in a semi-arid region, and (ii) to evaluate, in such a region, entrainment parametrizations used in the literature.

We took advantage of a statistical study (Canut et al. 2010) based on measurements from the French ATR aircraft during the African Monsoon Multidisciplinary Analysis (AMMA) experiment (Lebel et al. 2010). This study showed the presence of 'dry tongues', which are intrusions of dry air from the SAL into the PBL. They participate in the entrainment process at the PBL top and are responsible for large moisture fluxes in the upper PBL due to the large difference in humidity between the SAL and the PBL. This study showed a particularly thick entrainment zone in the Sahelian area during the observation period and a large contribution of the dry tongues to the PBL characteristics and structure.

To complete the study based on the observations, a LES was used of one observed day so as to analyze the evolution of the entrainment during the day. The novelty also lies in the use 
of sheared convective boundary-layer observations to evaluate the LES and the parametrization found in the literature. Here, observations and LES are used together in order to better understand the physical processes and test the sensitivity of the existing parametrizations. A first LES is designed, based on observations of 5 June 2006, a case with significant monsoonal wind at midday during the pre-onset period. Once the simulation has been evaluated with observations, with a focus on the representation of the entrainment structures, we extend this case by using a large range of initial vertical profiles of thermodynamic and wind speed. This generates a set of eight sensitivity tests. This sensitivity study enables us to determine the effect of the wind shear and scalar gradients at the PBL top on the entrainment processes and to evaluate recent entrainment parametrizations. The paper is structured as follows: in Sect. 2, the experimental conditions and the LES set-up are presented. Section 3 describes the impact of dry air on the PBL structure during 5 June 2006 with observations and large-eddy simulations. The results of the sensitivity study on the parametrizations of entrainment are discussed in Sect. 4. Conclusions are summarized in the final section.

\section{Experimental Conditions and Numerical Set-Up}

\subsection{Observations Available for the Case Study}

The case study is 5 June 2006, a day characterized by a strong monsoonal flow that was identified by Couvreux et al. (2010) as a surge penetration of the monsoonal flow into the Harmattan flow. Such penetration is part of the variability of the monsoonal flow on a 3-5 day time scale, characterized by northern excursions of the monsoonal flow. During the day of 5 June 2006, the ATR-42 research aircraft performed a boundary-layer flight in the vicinity

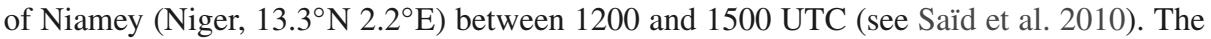
aircraft flew several $80-\mathrm{km}$-long legs in an east-west vertical plane. Three radiosoundings were launched at 0600, 1130 and 1800 UTC at Niamey airport by the Atmospheric Radiation Measurement (ARM) facility. Surface fluxes are observed at Niamey and Wankama; two stations $60 \mathrm{~km}$ apart. We also used the data from the wind profiler operated in Niamey by the ARM mobile facility (see Kalapureddy et al. 2010).

\subsection{Reference LES}

\subsubsection{Model and Domain}

The model used in this study is the LES version of the non-hydrostatic model Meso-NH, the dynamical part of which is presented by Lafore et al. (1998). The three-dimensional turbulence scheme is based on that proposed by Redelsperger and Sommeria (1982) and is discussed in detail by Cuxart et al. (2000). It is based on a prognostic equation for subgrid kinetic energy and incorporates the effect of thermal stratification on subgrid fluxes by varying the Prandtl and Schmidt numbers. This model is operated without a radiation scheme and clear sky is considered.

A $10 \mathrm{~km} \times 10 \mathrm{~km} \times 5 \mathrm{~km}$ domain is used, and the set-up of the simulation is very similar to that of Couvreux et al. (2005). The horizontal resolution is $100 \mathrm{~m}$ and a flat domain is considered, which is indeed a characteristic of the region. A vertical stretched grid of 60 levels is used with resolution finer than $50 \mathrm{~m}$ up to an altitude of $1,000 \mathrm{~m}$, and equal to $100 \mathrm{~m}$ higher up. At the top of the domain, in order to avoid the reflection of gravity waves, an absorbing layer of $1 \mathrm{~km}$ depth is added, where the fields are nudged towards the mean 
profiles. Two additional numerical experiments with vertical or horizontal resolutions that were twice as fine are performed for this case (not shown). They show small differences in the thermodynamical parameters in comparison to the reference simulation suggesting that $100 \mathrm{~m}$ is fine enough to study the turbulent processes. The lateral conditions are cyclic and the simulation lasts for $12 \mathrm{~h}$ from $0600 \mathrm{UTC}$ to $1800 \mathrm{UTC}($ local time $=\mathrm{UTC}+1)$. The simulation starts from horizontally homogeneous conditions (detailed in the next section), except for a random $\theta$ perturbation of $0.1 \mathrm{~K}$ applied to each grid point of the lowest level. Large-scale advection of heat and moisture is taken into account, since observations indicate that advection is not negligible during the observing period. This is discussed in the next section.

\subsubsection{Initial Conditions and Forcing}

The initial vertical profiles shown in Fig. 2 are based on the ECMWF reanalyzes (AgustiPanareda et al. 2010) at 0600 UTC. In the simple framework adopted here, large-scale advection has to be prescribed. The values are based on the ECMWF reanalysis together with inferences from aircraft observations and prescribed every $3 \mathrm{~h}$. It is important to note that no advection is prescribed above 2,000 m. As shown in Fig. 2, the horizontal advection of the potential temperature and the water vapour mixing ratio are large, due to the strong monsoonal flow observed that day. The monsoon wind (about $7 \mathrm{~m} \mathrm{~s}^{-1}$ wind speed) tends to cool $\left(0.3 \mathrm{~K} \mathrm{~h}^{-1}\right.$ at maximum) and moisten $\left(0.3 \mathrm{~g} \mathrm{~kg}^{-1} \mathrm{~h}^{-1}\right.$ at maximum) the air near the surface in the morning. The moisture advection changes sign near the PBL top due to the presence of the Harmattan wind (bringing dry air from the north).

An idealized surface sensible heat flux is prescribed with a maximum of $400 \mathrm{~W} \mathrm{~m}^{-2}$ at midday, consistent with observations from the ARM mobile facility in Niamey, close to the area overflown by the aircraft. This choice provided a good fit of the simulated thermodynamic profiles and PBL top-level estimates with the observations. Sensitivity tests with 300 and $350 \mathrm{~W} \mathrm{~m}^{-2}$ peak fluxes reflecting, respectively, the flux measured at Wankama (Fig. 3) or the average between Niamey and Wankama observations show that these two surface fluxes are not large enough to correctly warm the boundary layer. Note that, here the impact of radiation on this boundary layer has been neglected. Nevertheless, its impact has been evaluated and contributes $0.2-0.4 \mathrm{~K}$ to the warming. This suggests that, in this case, a lower sensible heat flux could have been prescribed. During this time of the year, before the monsoon onset, the humidity surface heat flux is close to zero and is chosen equal to zero in the LES. Also, the large-scale subsidence is neglected and this point is discussed later.

\subsection{Validation of the Simulation}

Careful attention is paid to thoroughly validating the LES with the numerous observations available for the day, the focus being on the mean vertical structure, the PBL top height, and flux and variance profiles.

\subsubsection{Mean Vertical Structure}

Figure 4 shows the water vapour mixing ratio $\left(r_{\mathrm{v}}\right)$, potential temperature $(\theta)$, and zonal $(U)$ and meridional $(V)$ wind components observed by the aircraft and simulated by the LES model at midday. In this figure, the aircraft observations correspond to a vertical exploration with stacked legs, on which the horizontal variability at the different levels can be seen. The LES profiles correctly fit the ARM radiosoundings at 1130 and 1730 UTC (not shown). 

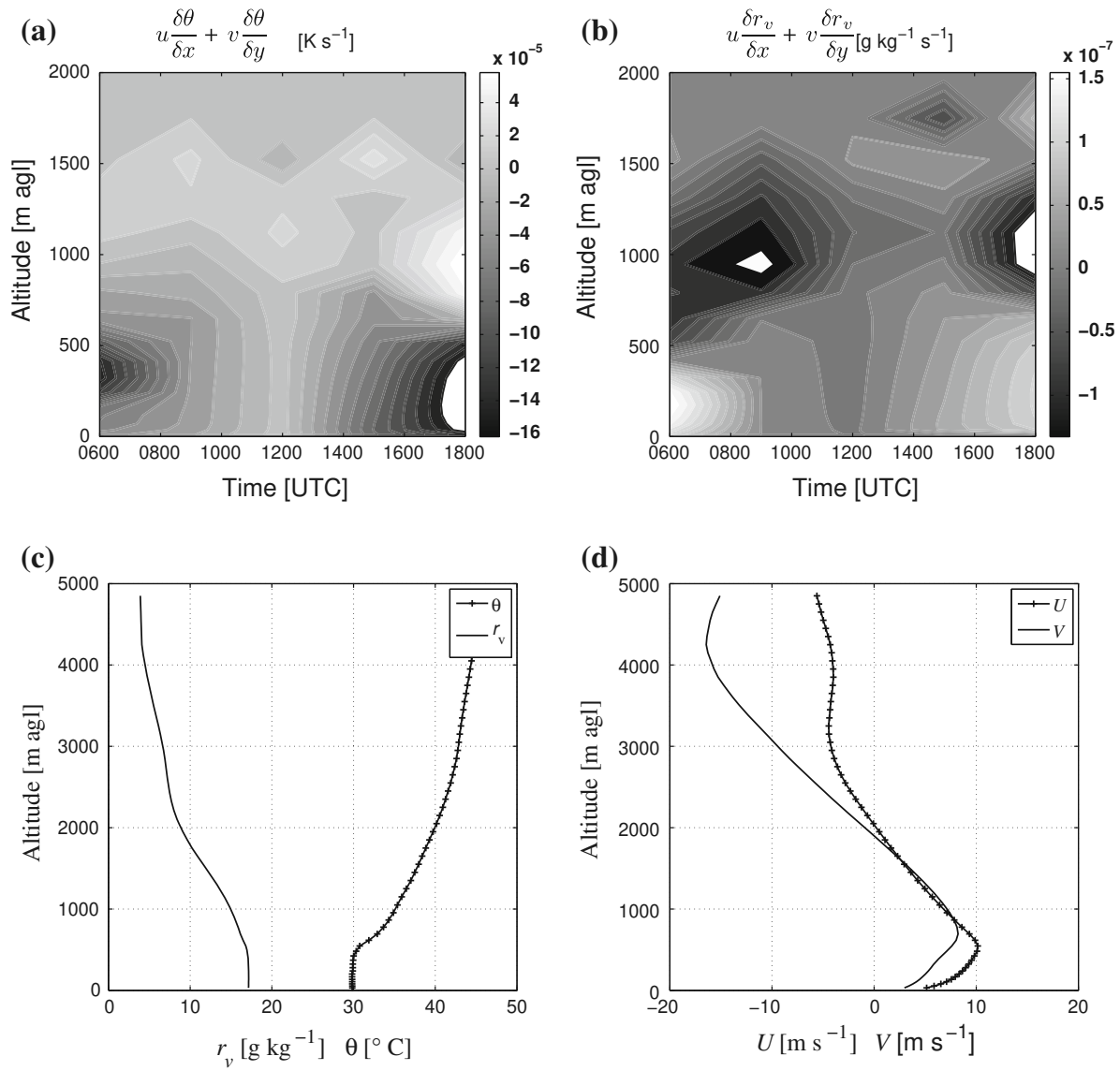

Fig. 2 Profiles of large-scale advection of a potential temperature and $\mathbf{b}$ water vapour mixing ratio prescribed every $3 \mathrm{~h}$ and interpolated in between. Initial profiles of $\mathbf{c}$ potential temperature and water mixing ratio and $\mathbf{d}$ zonal and meridional wind component, prescribed at 0600 UTC

Fig. 3 Observed (grey and black lines) and prescribed (dashed line) surface sensible heat flux

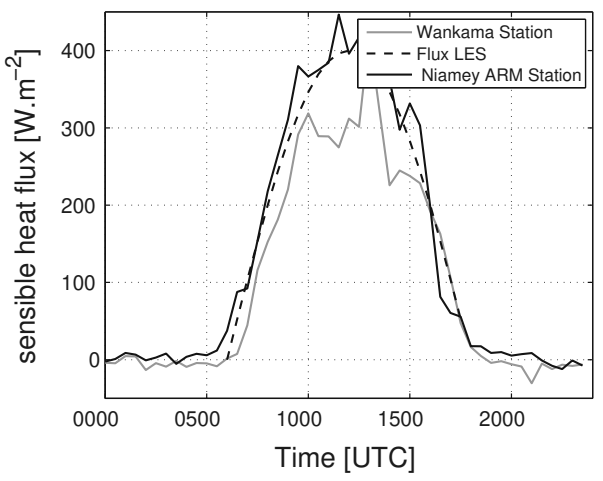

For $\theta, r_{\mathrm{v}}$ and $U$, the jumps across the PBL top inversion are well predicted $\left(4 \mathrm{~K}, 6 \mathrm{~g} \mathrm{~kg}^{-1}\right.$ and $9 \mathrm{~m} \mathrm{~s}^{-1}$, respectively). The variability found among the observations is also fairly well reproduced in the LES since the aircraft observations are confined within the range of simu- 
(a)

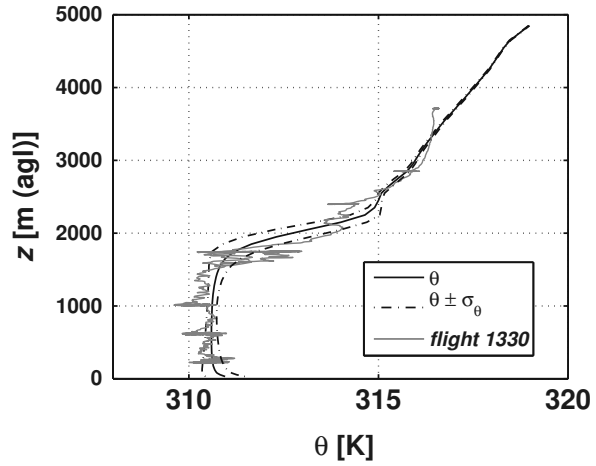

(c)

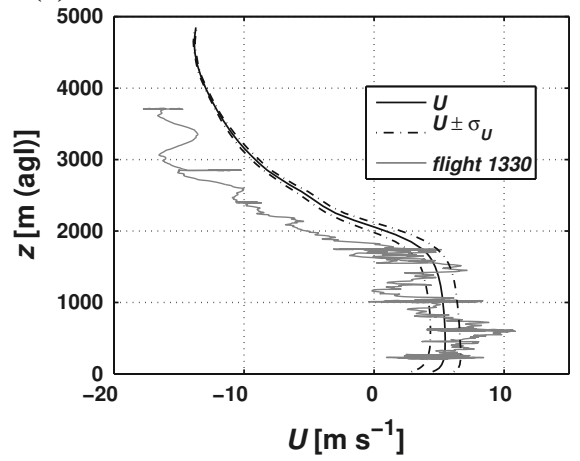

(b)

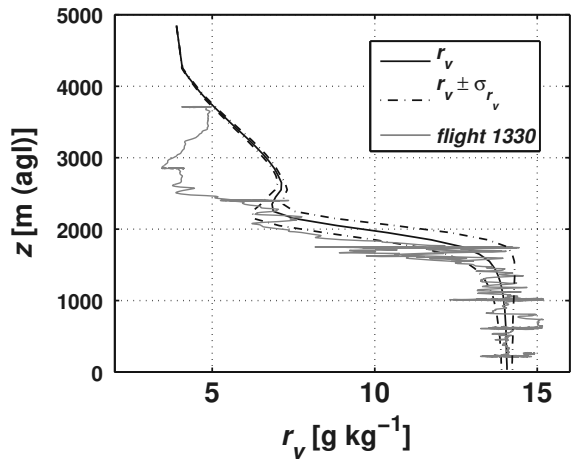

(d)

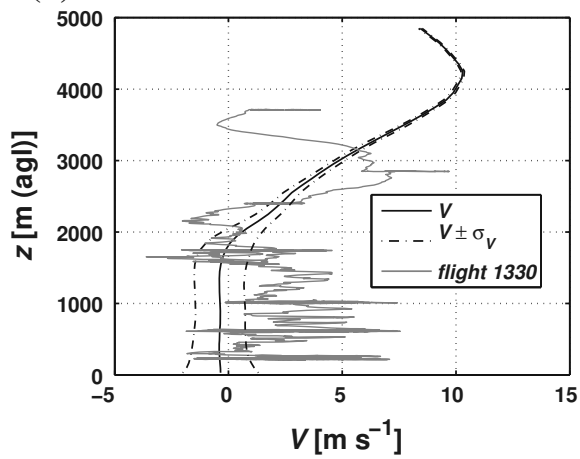

Fig. 4 Profiles of $\mathbf{a} \theta, \mathbf{b} r_{\mathrm{V}}, \mathbf{c}$ zonal and $\mathbf{d}$ meridional wind component (black) averaged in the LES model between 1300 and $1400 \mathrm{UTC}$, and (grey) observed during the flight around $1330 \mathrm{UTC}$ at $1 \mathrm{~s}^{-1}$. The dashed lines represent the variability ( \pm standard deviation) in the simulation domain

lated values most of the time. For the meridional wind component $(V)$ more differences are found between observations and LES (Fig. 4d).

\subsubsection{PBL Top Level}

The evolution of the PBL top is crucial, in particular to evaluate the entrainment flux, since it is closely linked with entrainment processes. Figure 5 compares four different methods to obtain the PBL depth $Z_{i}$, by using LES results and observations (wind profiler and soundings). The PBL top can be defined as in Sullivan et al. (1998) by: (i) the height of the minimum buoyancy flux, (ii) the height of maximum gradient of potential temperature, (iii) the height where the virtual potential temperature becomes greater than the average virtual potential temperature of the levels below: $\theta(z)>\bar{\theta}+0.25$, (iv) the height of maximum radar reflectivity of windprofilers (Angevine et al. 1994). The PBL height obtained from the UHF data (iv) has the same value as that for the method of the mean virtual potential temperature (iii). As expected, this method provides a smaller PBL height than the maximum gradient method (ii), and the flux method (i) gives intermediate values. Both observations provide consistent estimates of the height of the mixed-layer top and the LES estimates also match the observations. The wind profiler data confirm the rapid evolution of the PBL simulated by LES 


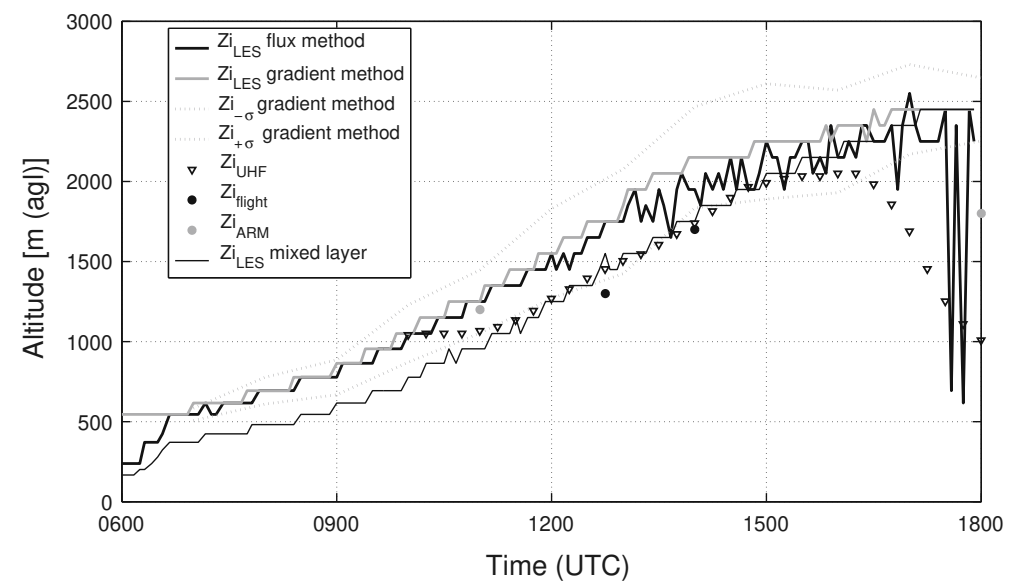

Fig. 5 Evolution of the PBL height on 5 June 2006 from (grey dots) the radiosoundings at the ARM station, (black dots) the aircraft observations and (inverted triangle) the wind profiler observations at Niamey every $15 \mathrm{~min}$. In the LES the PBL height is obtained with (thin black line) the top of the mixed layer method, (black line) the minimum of buoyancy flux method, (grey lines) the method of the maximum potential temperature gradient. Dashed grey lines show the variability of $Z_{i}$ obtained with the maximum potential temperature vertical gradient over the LES domain

between 1100 UTC and 1600 UTC. Considering all the available data, PBL growth rate is estimated at around $0.12 \mathrm{~m} \mathrm{~s}^{-1}$ over this time interval on that day. Note that in the following, definition (i) is used for the LES data and definition (iii) for the aircraft or radiosounding data.

\subsubsection{Fluxes}

The vertical profiles of the buoyancy and humidity fluxes observed by aircraft in the boundary layer are linear with height (not shown), and allow the estimation of the entrainment rate by extrapolating the buoyancy flux at the surface and at the top of the PBL. The observed sensible heat flux extrapolated to the surface is far smaller than the LES flux that had been prescribed according to the ground station observations in Niamey (Table 1). However, such a low value of the surface flux could not be used in the simulation since it provides incorrect thermodynamic structure and PBL top height. Several hypotheses can be invoked to explain this discrepancy. The aircraft sampling is one-dimensional whereas the simulation is twodimensional, and may lead to an underestimation of the surface flux as shown by Lothon et al. (2007). In their study, the difference is partly linked to the presence of organized two-dimensional structures that make the turbulent fields anisotropic in the boundary layer. Moreover, the aircraft flux sample integrated a variety of surface fluxes (see, for instance, the discrepancy between Niamey and Wankama stations, $60 \mathrm{~km}$ apart), which is different from a homogenous surface. However, the difference between 135 and $350 \mathrm{~W} \mathrm{~m}^{-2}$ is too large to be explained by these hypotheses alone. Note that this day is characterized by a larger underestimation of the aircraft measurements (Saïd et al. 2010). The simulation requires higher surface fluxes to produce sufficient heating and growth of the boundary layer. Decreasing the advection term (which cools and moistens the boundary layer) does not improve the comparison. Frequently during the pre-onset period, the surface heat fluxes measured by aircraft underestimate (five flights out of eight) those measured at Wankama. Also, for this day, when the horizontal legs are divided into two parts, Saïd et al. (2010) obtained two different estimations of the surface 
Table 1 Observed and simulated values of sensible $(H)$ and latent $(L E)$ heat flux at the surface and at the PBL top for 5 June 2006 at 1400 UTC

\begin{tabular}{lcccccc}
\hline & At surface & & & & At $Z_{i}$ & \\
\cline { 2 - 7 } & $\begin{array}{l}\text { Observed at } \\
\text { Wankama }\end{array}$ & $\begin{array}{c}\text { Observed } \\
\text { at Niamey }\end{array}$ & $\begin{array}{l}\text { Observed } \\
\text { by aircraft }\end{array}$ & LES & $\begin{array}{l}\text { Estimated } \\
\text { by aircraft }\end{array}$ & LES \\
\hline$H\left(\mathrm{~W} \mathrm{~m}^{-2}\right)$ & 240 & 350 & 135 & 350 & -43 & -40 \\
$L E\left(\mathrm{~W} \mathrm{~m}^{-2}\right)$ & 35 & 5 & 0 & 0 & 753 & 625 \\
\hline
\end{tabular}

heat flux. In contrast, the moisture fluxes at the surface and at the PBL top are correctly reproduced (not shown); the humidity flux at the PBL top is large whereas it is negligible at the ground, as observed. This case is similar to the entrainment-drying prototype boundary layer studied by Mahrt (1991).

\subsubsection{Variances}

Figure 6 shows the vertical profiles of variances of $\theta, r_{\mathrm{v}}$ and $w$ at midday. In the LES, the maxima of the potential temperature variance and the water vapour mixing ratio variance are found in the entrainment zone. However, the few points observed in this layer, where scalars vary greatly, did not allow a complete comparison with the LES data. Note that Turner et al. (2010) observed the same order of magnitude of scalar variances for a convective boundary-layer case with Raman lidar operated over the Southern Great Plains at Oklahoma, USA. These profiles result from large exchanges between the PBL and the free troposphere. At the surface, both the simulation and the observations show small values of the water vapour mixing ratio variance due to the dryness of the soil and the resulting close-to-zero latent heat fluxes. This means that the water vapour mixing ratio fluctuations within the PBL are only generated in the entrainment zone. In contrast, the potential temperature fluctuations are generated both at the surface and at the entrainment zone. In consequence, the potential

(a)

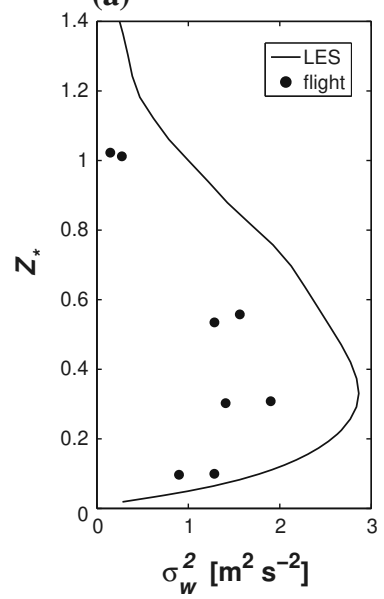

(b)

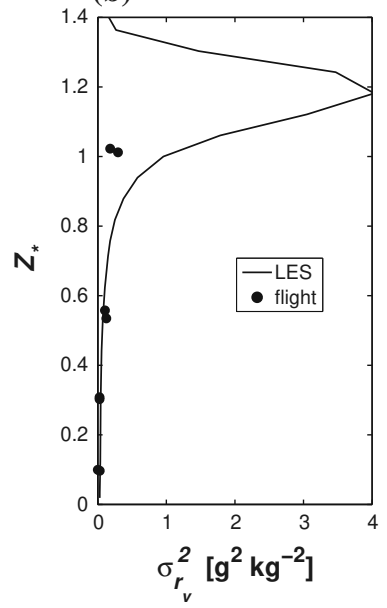

(c)

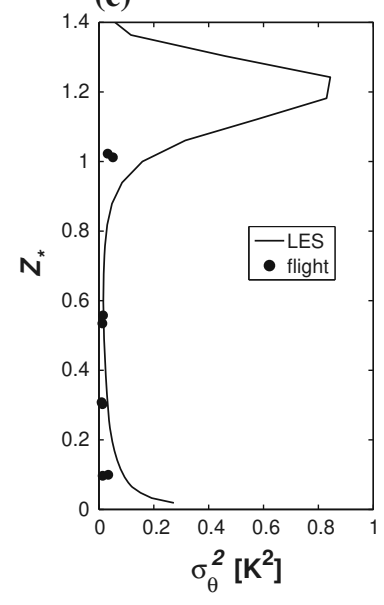

Fig. 6 Profiles of the simulated (solid line) and observed (dots) variance of a vertical velocity, $\mathbf{b}$ water vapour mixing ratio and $\mathbf{c}$ potential temperature for 5 June 2006 around $1330 \mathrm{UTC} ; z_{*}$ is the reduced height $\left(Z / Z_{i}\right)$ 
temperature variance is found to be large both at the surface and close to the PBL top. The observations show a similar profile of $\sigma_{\mathrm{w}}$ with a maximum at $600 \mathrm{~m}\left(0.3 Z_{i}\right)$ but the variance is twice as large in the simulation. A test simulation with smaller (reduced by $25 \%$ ) sensible heat flux gives a vertical velocity variance closer to the aircraft observations but the boundary-layer depth and the mean parameters are then underestimated (not shown). Since the moisture fluxes are similar, this implies that the $w-r_{\mathrm{V}}$ correlation coefficients are underestimated in the LES (not shown). We did not find any explanation for this.

Despite the difference between the observations and the LES concerning the surface heat flux, we obtain a similar structure for the mean parameters in the mixed layer and, consequently, the LES results can be used to better understand and evaluate the entrainment processes in this case.

\section{Impact of Entrainment of Dry Air on the PBL Structure: Case of 5 June 2006}

Large-eddy simulation and aircraft observations provide information about the structure of the PBL and about the role of the dry tongues. During this period, the surface latent heat flux is close to zero. The main source of humidity variability in the PBL is the dry air entrained from the free troposphere into the PBL, which generates a large latent heat flux at the top. In this semi-arid region, and before the humid period, there is no moisture source at the ground. However the boundary layer moisture derives from the monsoonal flow, which is particularly enhanced during the night due to the low-level jet. During daytime, this moisture is vertically redistributed to the free troposphere by dry convection (Lothon et al. 2008). Meanwhile the PBL is dried under the influence of dry tongues that penetrate into it through entrainment. The analysis of the fluctuations in potential temperature, water vapour mixing ratio and vertical velocity, using both the observations (Canut et al. 2010) and the LES (Couvreux et al. 2007), highlights the presence of dry intrusions at the PBL top that penetrate to the middle of the PBL, and even lower (Lohou et al. 2010). The variances and fluxes within the CBL discussed above result from the impact of these dry tongues. In particular, the large moisture flux values at the PBL top are due to negative fluctuations of vertical velocity and water vapour mixing ratio, which correspond to the exchanges between dry SAL and moist PBL through the dry tongues.

Thus, dry tongues contribute to the vertical redistribution of the water vapour and other scalars. Close to the PBL top, they have a typical width of $500 \mathrm{~m}$ and the distance between them is $2 \mathrm{~km}$ both in observations (Canut et al. 2010) and in our numerical simulations.

In order to estimate the contribution of dry tongues to the variances relative to the contribution of thermals, a conditional analysis on the fluctuations $w^{\prime}, \theta^{\prime}$ and $r_{\mathrm{v}}^{\prime}$ is made following Grossman and Nimal (1995). Here we compare the observations to the LES. Fluctuations $X^{\prime}$ of a variable $X$ are computed as: $X^{\prime}=X-\bar{X}$ where $\bar{X}$ is the mean over a leg (for aircraft measurements) or over the domain (for LES) at each height. We define three classes: thermals with $w^{\prime}>0$ and $\theta^{\prime}>0$, dry tongues with $w^{\prime}<0, r_{\mathrm{v}}^{\prime}<0$ and $\theta^{\prime}>0$, and the remaining population in a third class.

With this conditional sampling, the simulation fits aircraft observations for 5 June 2006 very well, as shown in Fig. 7. The conditional sampling of the fluctuations reveals that the dry tongues are not necessarily the most numerous turbulent structures (Fig. 7c). At the PBL top, they represent $25 \%$ of the data points as do the thermals at the same level. The difference is that the thermal contribution decreases from the surface (40\%) to $Z_{i}$ whereas the dry tongue contribution increases, consistent with the flux profiles. The contribution to the variances illustrates the importance of the sources of the fluctuations for both scalars: thermals are the main contribution to the temperature variance in the lower half of the PBL (60\%) whereas 
(a)

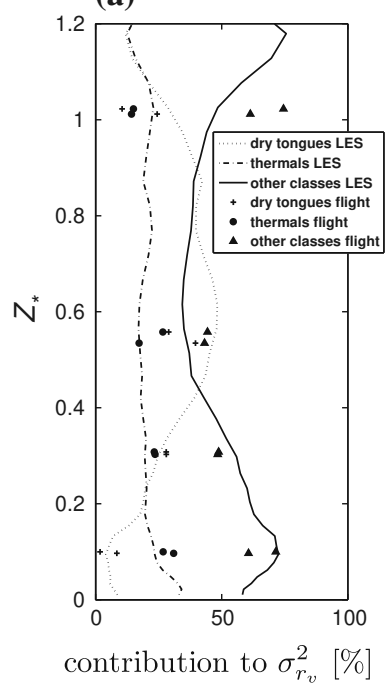

(b)

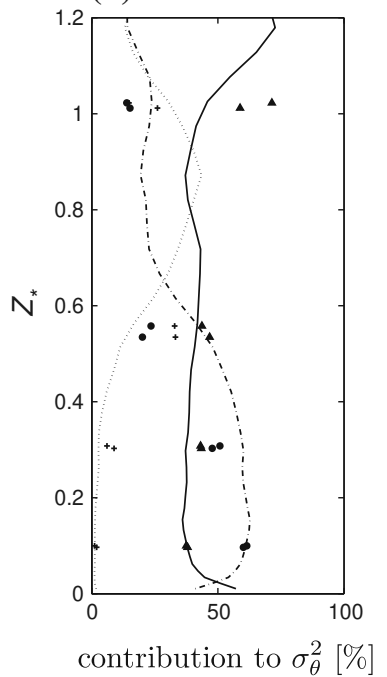

(c)

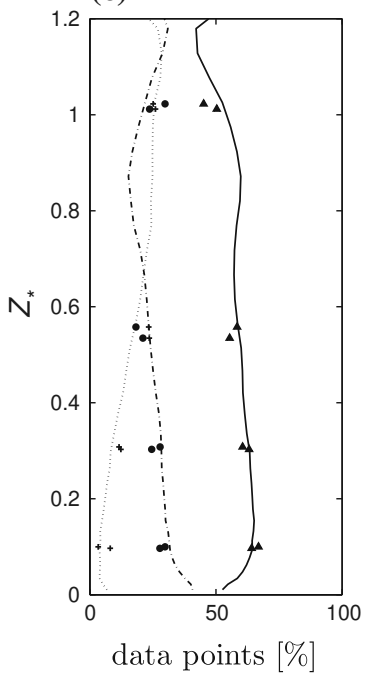

Fig. 7 Contribution of the different classes around 1330 UTC to a humidity variance, $\mathbf{b}$ potential temperature variance. $\mathbf{c}$ Distribution of data points over the different classes according to (solid line) LES and (crosses) aircraft observations for 5 June 2006

their contribution is only $25 \%$ in the higher half. The contribution of the dry tongues, which is negligible up to $0.5 Z_{i}$, reaches almost $50 \%$ at $0.9 Z_{i}$. Similarly, the contribution of the dry tongues to $\sigma_{r_{\mathrm{v}}}$ is around $50 \%$ from $0.5 Z_{i}$ to $0.9 Z_{i}$, whereas the contribution of thermals remains low and constant in the whole PBL (lower than 25\%). In fact, according to Couvreux et al. (2007) and Canut et al. (2010), close to half of the most negative intense fluctuations in vertical velocity $\left(w<-\sigma_{\mathrm{w}}\right)$ at the PBL top are associated with positive fluctuations of potential temperature and negative fluctuations of water vapour mixing ratio (not shown here), which highlights the large contribution of these dry tongues to the exchanges. During this period of the year, before the monsoon onset, the surface is very dry, vegetation is sparse and the only source of humidity fluctuations is at the PBL top, since the free troposphere is far drier than the PBL. The fact that the PBL remains moist from one day to the next, in spite of the vertical transport by the dry tongues, is a result of the advected moist monsoonal air in the lower layers (Fig. 2), which is reinforced at night by the low-level nocturnal jet.

The surface and PBL top flux values allow us to estimate the entrainment rate defined by Eq. 1. Aircraft observations in the study area often showed values of $\beta$ larger than 0.2 (Canut et al. 2010; Saïd et al. 2010) with a large spectrum of values from close to 0 to 0.48 during this season. For this 5 June case, we find an entrainment rate close to 0.3 with a random error close to $30 \%$ around 1330 UTC, larger than the 0.2 often associated with the purely convective PBL. With the LES, the entrainment rate increases during the day but remains smaller than 0.2. The difference between LES and aircraft observations is linked to the fact that the surface heat flux prescribed in the LES is larger than that observed by the aircraft.

\section{Evaluation of Some Parametrizations of Entrainment in the Semi-Arid Region}

To improve the understanding of the entrainment processes within the Sahelian boundary layer, several sensitivity tests are performed in order to extend the range of initial conditions 
prescribed for the 5 June case by mean conditions encountered during the pre-onset period. This set of data provides a range of entrainment rates that allows several parametrizations of entrainment processes to be evaluated.

\subsection{Sensitivity Tests}

In spite of the discrepancies discussed before, the LES PBL structure and dynamics fit the observations well enough for us to pursue our analysis with a sensitivity study. A set of eight sensitivity tests are designed with a large range of thermodynamic gradients and wind shears between the PBL and the free atmosphere, in order to evaluate the effect of the wind shear on the entrainment processes. The conditions covered the conditions encountered during eight flights within the pre-onset period (Canut et al. 2010) including the previous 5 June case. This approach is different from the idealized initial conditions often used in the literature (Fedorovich et al. 2004; Pino et al. 2006; Kim et al. 2003) since it is based on real observations.

For the various tests, no large-scale advection is prescribed in order to avoid a supplementary source of variability. The simulation without advection has a warmer $(0.8 \mathrm{~K})$ and deeper (200-400 m) mixed layer than the simulation with advection. A homogeneous time-varying sensible heat flux with a maximum of $400 \mathrm{~W} \mathrm{~m}^{-2}$ is used as in the case of 5 June. This is an idealization, since the surface flux intensity varies from day to day. Nevertheless, the objective here is to assess the impact of various realistic initial conditions on the entrainment process.

Figure 8 shows the different initial profiles used that correspond to the simplified profiles observed during the pre-onset period. Starting with run02 and run03, which correspond respectively to the reference test ( 5 June), and the reference test without advection, we change the initial profiles of potential temperature and water vapour mixing ratio for tests 44,48 and 49 and the initial profiles of meridional and zonal wind components for tests 45, 46 and 47. When the profiles of potential temperature and water vapour mixing ratio are modified, the wind profiles of the reference simulation are used and vice versa. These six sensitivity tests and the 5 June 2006 simulation, with and without advection, form our full set of simulations, summarized in Table 2. Note that the reference test conditions ( 5 June) represent extreme values relative to the conditions of the pre-onset period, except for $\theta_{\mathrm{v}}$.

\subsection{Entrainment Velocity Analysis: ZOM Versus FOM Approximation}

To quantify entrainment, the entrainment velocity is used, which estimates the engulfment within the PBL of air from the free troposphere:

$$
w_{\mathrm{e}}=\frac{\partial Z_{i}}{\partial t}-w_{\mathrm{h}}
$$

where $w_{\mathrm{h}}$ is the large-scale vertical velocity; $w_{\mathrm{h}}$ is usually small (Garratt 1992). ECMWF and NCEP analyzes were used to estimate $w_{\mathrm{h}}$ and we obtained absolute values smaller than $10 \mathrm{~mm} \mathrm{~s}^{-1}$ with a large variability over time, often different from one model to the other. Therefore, in this study, $w_{\mathrm{h}}$ is assumed to be zero.

In the $\mathrm{ZOM}$ approach, $w_{\mathrm{e}}$ can be estimated by the negative ratio between the flux of a scalar quantity at the inversion and the jump in the scalar $\left(\theta, r_{\mathrm{v}}\right.$ or concentration of trace gas) (Lilly 1968; Faloona et al. 2005; Lenschow et al. 1999):

$$
\left.w_{\mathrm{e}}\right|_{\mathrm{ZOM}} \simeq-\frac{\left.\overline{w s}\right|_{i}}{\Delta s}
$$


(a)

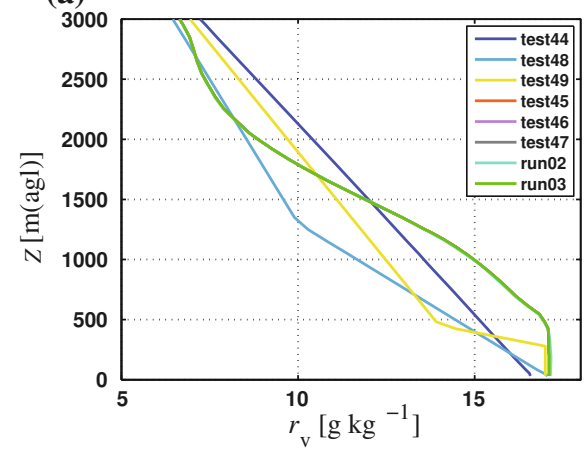

(c)

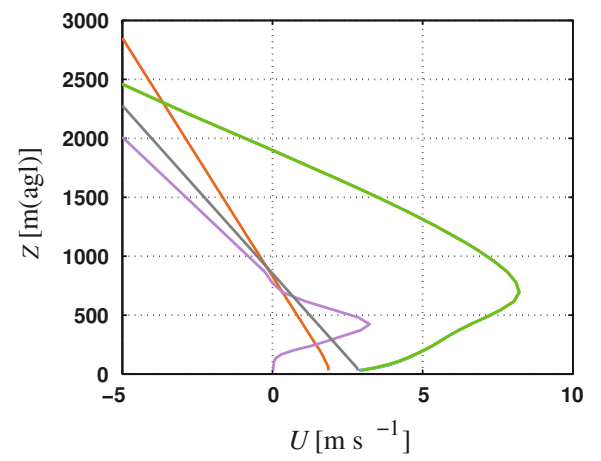

(b)

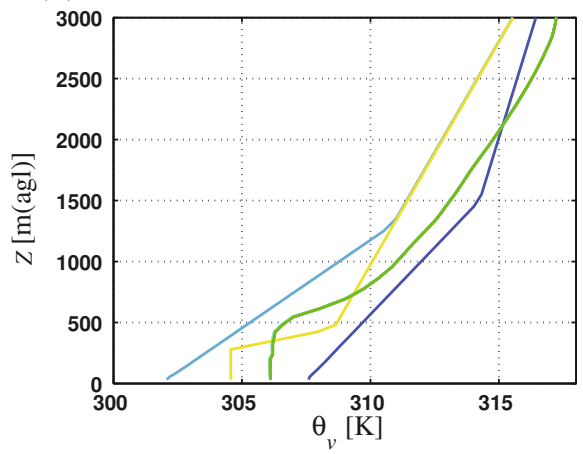

(d)

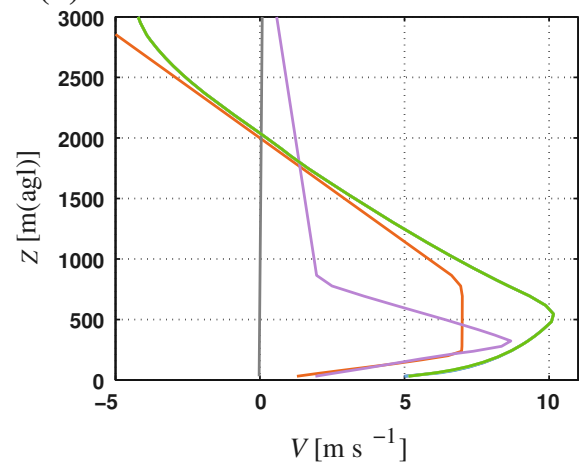

Fig. 8 Initial profiles of a potential temperature, $\mathbf{b}$ water vapour mixing ratio, $\mathbf{c}$ zonal and $\mathbf{d}$ meridional wind components for 8 LES runs (initial conditions are similar for run02 and run03 except for the advection). The green lines correspond to run02 (reference simulation) and to run03 (reference simulation without large-scale advection)

Table 2 Initial conditions at 0600 UTC: $Z_{i}(\mathrm{~m})$ : PBL height; adv: large-scale advection; $\theta_{0}(\mathrm{~K}): \theta$ at the surface; $\delta \theta /\left.\delta z\right|_{0}\left(10^{-3} \mathrm{~K} \mathrm{~m}^{-1}\right)$ : lapse rate within unmixed PBL; $\delta \theta / \delta z\left(10^{-3} \mathrm{~K} \mathrm{~m}^{-1}\right)$ : lapse rate in the free troposphere; $\delta r_{\mathrm{v}} /\left.\delta z\right|_{0}\left(10^{-3} \mathrm{~g} \mathrm{~kg}^{-1} \mathrm{~m}^{-1}\right), \delta r_{\mathrm{v}} / \delta z\left(10^{-3} \mathrm{~g} \mathrm{~kg}^{-1} \mathrm{~m}^{-1}\right)$ : close-to-surface and free-troposphere vertical gradient of water vapour mixing ratio; $\mathrm{WSPD}_{\max }\left(\mathrm{m} \mathrm{s}^{-1}\right)$ : maximum of wind speed over vertical domain

\begin{tabular}{crllccccc}
\hline Name & $Z_{i}$ & Adv & $\theta_{0}$ & $\left.\frac{\delta \theta}{\delta z}\right|_{0}$ & $\gamma=\frac{\delta \theta}{\delta z}$ & $\left.\frac{\delta r_{\mathrm{V}}}{\delta z}\right|_{0}$ & $\frac{\delta r_{\mathrm{V}}}{\delta z}$ & WSPD $_{\max }$ \\
\hline run02 & 500 & Yes & 303.0 & & 4.2 & & -2.5 & 12.0 \\
run03 & 500 & No & 303.0 & & 4.2 & & -2.5 & 12.0 \\
test44 & 0 & No & 304.5 & 5.0 & 1 & -3.2 & -3.2 & 12.0 \\
test48 & 0 & No & 299.0 & 7.7 & 2.9 & -5.5 & -2.5 & 12.0 \\
test49 & 300 & No & 303.2 & & 2.9 & & -2.3 & 12.0 \\
test45 & 500 & No & 303.0 & & 4.2 & & -2.5 & 7.0 \\
test46 & 500 & No & 303.0 & & 4.2 & & -2.5 & 6.0 \\
test47 & 500 & No & 303.0 & & 4.2 & & -2.5 & 3.0 \\
\hline
\end{tabular}


(a)

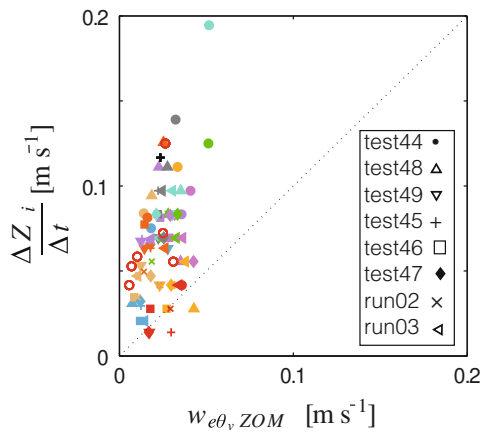

(c)

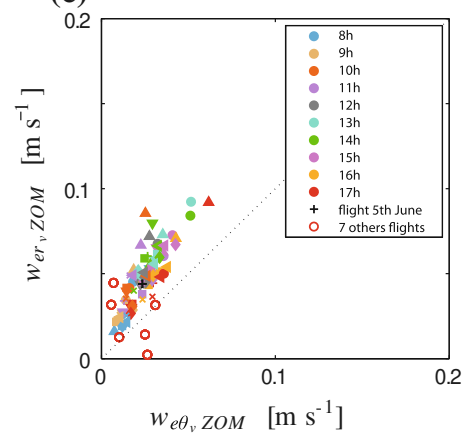

(b)

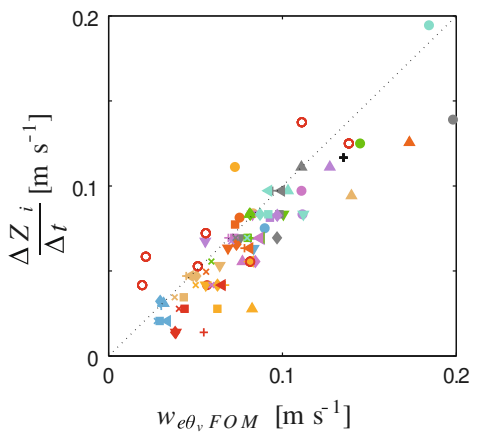

(d)

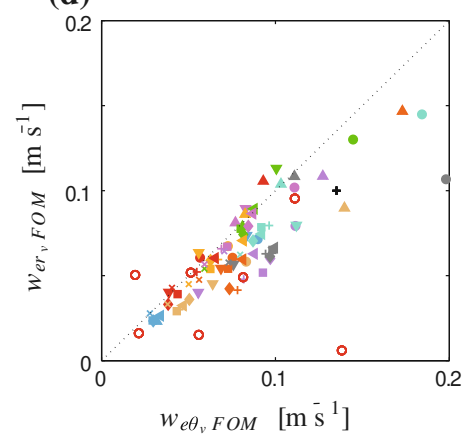

Fig. 9 Comparison between $\Delta Z_{i} / \Delta t$ and $w_{\mathrm{e}}$ calculated by using the potential temperature, based on a a ZOM model and b a FOM model. c, d compare $w_{\mathrm{e}}$ calculated with two different scalars (the virtual potential temperature and the vapour mixing ratio) with a ZOM model and a FOM model respectively. Colours refer to the time of day and symbols to the sensitivity tests. The aircraft estimates are represented by a black cross ( 5 June) and red circles (other flights)

where 's' can be any scalar quantity. The scalar jumps are defined in the LES using two different methods: first, by the area of the negative buoyancy flux, and second, by the distance between the top of the mixed layer (defined in Sect. 2.3) and the base of the free troposphere (defined by the point where the second derivative is null). No differences in the inversion jumps of the scalar quantities are found when using these two definitions and we chose to use the first method.

Here, $w_{\mathrm{e}}$ is estimated from our observations by using Eqs. 2 and 3, which provide two independent estimates. Assuming $w_{\mathrm{h}}=0$, in a ZOM approximation, $\partial Z_{i} / \partial t, w_{\mathrm{e}_{\theta_{\mathrm{v}}}}$ and $w_{\mathrm{e}_{\mathrm{r}}}$ should all be the same. ( $w_{\mathrm{e}_{\theta_{\mathrm{v}}}}$ and $w_{\mathrm{e}_{\mathrm{rv}}}$ represent $w_{\mathrm{e}}$ calculated with $\theta_{\mathrm{v}}$ and $r_{\mathrm{v}}$ respectively.) Figure 9a, c compare the two definitions. $\partial Z_{i} / \partial t$ observed is obtained from two estimates of $Z_{i}$, spaced approximately one hour apart: one is from the vertical sounding of the aircraft and the other from the time when the aircraft once again crosses the PBL during the descending portion of its vertical exploration with stacked legs. This allows $Z_{i}(t)$ to be estimated and $Z_{*}=Z / Z_{i}$, the reduced height, to be calculated for each horizontal leg. $\left.\overline{w \theta_{\mathrm{v}}}\right|_{0}$ and $\left.\overline{w \theta_{\mathrm{v}}}\right|_{i}$ are derived from the vertical profile of $\overline{w \theta_{\mathrm{v}}}$ (relative to $Z_{*}$ ). The jump of the virtual potential temperature across the inversion used in Eq. 3 is estimated with the sounding profile before and/or after the stacked legs, based on a zeroth-order or first-order jump approximation of 
the scalar profiles. This jump characterizes the strength of the inversion at the PBL top. In the LES simulation, $Z_{i}$, the jump of the virtual potential temperature across the inversion and the entrainment flux are averaged in the domain.

We find a large difference between $\partial Z_{i} / \partial t$ and the entrainment velocity defined by Eq. 3 (Fig. 9a). Equation 3, based on the ZOM approximation, largely underestimates the PBL growth, throughout the day. We also find a large departure between $w_{e_{\theta_{v}}}$ and $w_{\mathrm{e}_{\mathrm{r}_{\mathrm{v}}}}$ with the ZOM parametrization. Although the estimation of $w_{\mathrm{e}}$ obtained with the humidity provides higher values than those obtained with the potential temperature, the ZOM estimates remain smaller than the PBL growth. The main reason is that the ZOM model does not take the depth of the entrainment layer, $\delta$ (defined in Fig. 1) into account. During AMMA, the observations of the potential temperature vertical profiles indicate a particularly thick entrainment zone in the Sahelian PBL (see for example Fig. 4), which makes the ZOM approximation of an infinitesimally thin entrainment zone unrealistic. In Fig. 9, we have also added the results from the observations obtained in eight flights during the pre-onset period. The same conclusions can be drawn as with the simulations.

First Sullivan et al. (1998), then Pino and Vilà-Guerau de Arellano (2008) used a parametrization of $w_{\mathrm{e}}$ deduced from the FOM model. The parametrization, if subsidence is neglected, reads:

$$
\begin{aligned}
w_{\mathrm{e}} & \simeq \frac{\partial Z i}{\partial t} \\
& \simeq-\frac{\left.\overline{w \theta_{\mathrm{v}}}\right|_{i}}{\Delta \theta_{\mathrm{v}}}+\frac{\delta}{\Delta \theta_{\mathrm{v}}} \frac{\partial \overline{\theta_{\mathrm{v}}}}{\partial t} \\
& \simeq-\frac{\left.\overline{w r_{\mathrm{v}}}\right|_{i}}{\Delta r_{\mathrm{v}}}+\frac{\delta}{\Delta r_{\mathrm{v}}} \frac{\overline{\partial r_{\mathrm{v}}}}{\partial t} .
\end{aligned}
$$

Thus, a correction term is added to Eq. 3, which takes the entrainment zone depth into account, and depends on the time evolution of the scalar. Figure $9 \mathrm{~b}, \mathrm{~d}$ compare $\partial Z i / \partial t, w_{\mathrm{e} \theta_{\mathrm{v}}}$ and $w_{e_{\mathrm{r}_{\mathrm{v}}}}$ when a FOM is assumed. A closer fit is obtained for both LES and observations for the 5 June 2006. The correcting term from ZOM to FOM is smaller for $w_{e r_{\mathrm{v}}}$ than for $w_{\mathrm{e} \theta_{\mathrm{v}}}$, because the profile of the water vapour mixing ratio is closer to a zeroth-order jump model. However the FOM parametrization still significantly improves the comparison. The same parametrizations for $w_{\mathrm{e}}$ are tested for all the flights studied. For all the cases, the first-order approximation improves the relation between $\partial Z i / \partial t$ and $w_{\mathrm{e}}$. The correlation between $\partial Z i / \partial t$ and $w_{\mathrm{e}_{\mathrm{FOM}}}$ is not sensitive to the time of day. Note that this figure also confirms that $w_{\mathrm{h}}$ close to $10 \mathrm{~mm} \mathrm{~s}^{-1}$ can be neglected because of both the good fit obtained and the large scatter.

If we now consider the differences between the tests, we observe that the largest entrainment values are linked to situations with large wind shear at the surface and at the PBL top (tests 44, 48, 49 and run03). This result is in agreement with several studies that have investigated the role that wind shear plays in the PBL structure. Moreover, at constant wind shear, $w_{\mathrm{e}}$ is the largest when the thermodynamical gradients in the free troposphere are the largest.

In conclusion, the FOM, which takes finite entrainment zone depth into account, provides a better framework for estimating the entrainment velocity in the Sahelian PBL. This result shows that the thickness of the entrainment layer and the temporal evolution of scalars in the PBL are important parameters in the analysis of the entrainment processes and in attempts to estimate them with in situ observations. This cannot be generalized to other regions of the Earth where the ZOM may be sufficient to evaluate the entrainment process, depending on the scalar vertical profiles (for example, the stratocumulus-topped boundary layer). 
Nevertheless it is necessary to remain cautious with the FOM model for large entrainment values $\left(w_{\mathrm{e}}>0.1 \mathrm{~m} \mathrm{~s}^{-1}\right)$ as shown in Fig. 9b,d.

\subsection{Characteristics of Entrainment}

By using LES data and aircraft observations, we can study the relation between the entrainment processes, the wind shear in the entrainment zone and the dry tongues.

The wind change across the entrainment zone is calculated with $\Delta S=\left(\Delta U^{2}+\Delta V^{2}\right)^{\frac{1}{2}}$, where $\Delta U$ and $\Delta V$ are the jumps in zonal and meridional wind across $\delta$. The latter is defined by using the vertical profile of virtual potential temperature (see Fig. 1, method ii). As shown in Fig. 10, the entrainment rate $\beta$ increases when the wind difference increases, as already mentioned in several studies (Fedorovich and Conzemius 2008). It is important to note that during the last hour of the simulation, $\beta$ is poorly defined because the buoyancy fluxes both at the PBL top and at the surface are very small. In most cases, $\beta>0.2$ in both observations and LES, when the wind change across the entrainment zone is larger than $7 \mathrm{~m} \mathrm{~s}^{-1}$. As previously found in Fig. 9, tests 44 and 49 stand out by their large $\beta$ values. Also note that LES results for $\beta$ agree with the aircraft observed values. Linked with the result found by Conzemius and Fedorovich (2006a), which show that the surface wind shear has a mainly local effect, the tests with smaller surface wind shear (tests 45, 46 and 47) throughout the day have an entrainment rate similar to that of tests run02 and run03, which have twice the surface wind shear.

Previously, it was shown that large shear-stress values led to large $\beta$. Figure 11 illustrates the diurnal evolution of $\beta$, showing a strong increase in $\beta$ after midday and a large variability in the second part of the day with range $(0-0.4)$ similar to that found with the aircraft estimates during the AMMA experiment. The increase is linked to the fact that the boundary layer grows within the monsoon flow and reaches the shear level at the bottom of the SAL. This enhances the entrainment. Moreover, Fig. 11 highlights the shear contribution since tests 44,49 and run03 display the largest values of $\beta$, and all of them have the same initial wind profile. Test 44 has the least stable free troposphere $\left(0.001 \mathrm{~K} \mathrm{~m}^{-1}\right)$ and consequently the entrainment rate is the largest among all the simulations. Between tests run02 and run03, the advection plays a significant role. The simulated boundary layer without advection (run03) is warmer and deeper, having a larger wind shear at the inversion than when advection is present (run02) and a larger $\beta$. Tests 46 and 47 give the lowest values of $\beta$ with the same

Fig. 10 Entrainment rate as a function of wind shear at the PBL top. The black cross symbol refers to the 5 June case and the red circles to the seven flight observations

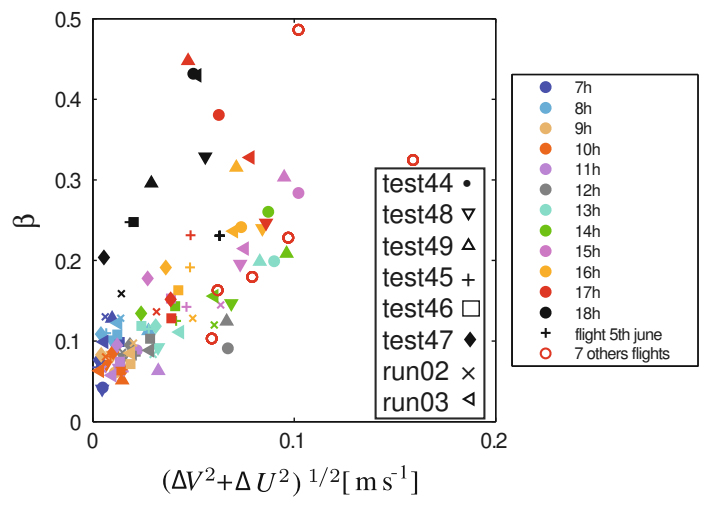




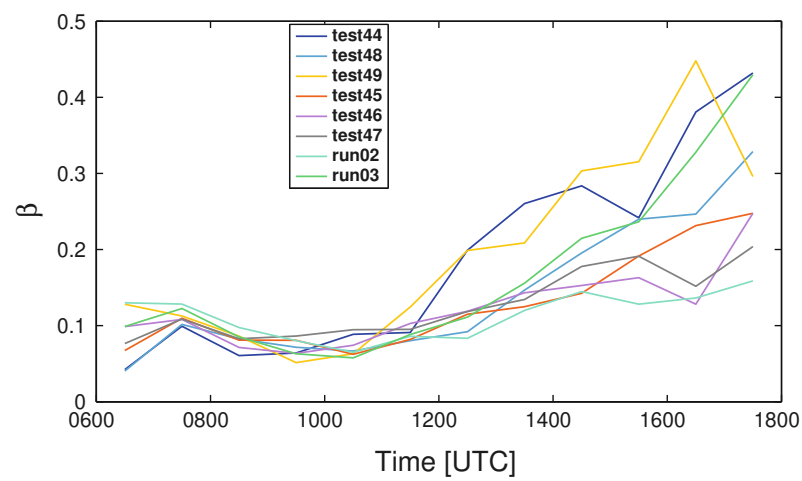

Fig. 11 Temporal evolution of $\beta$ for the eight sensitivity tests of the LES

(a)

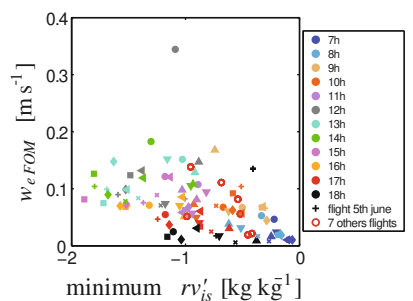

(b)

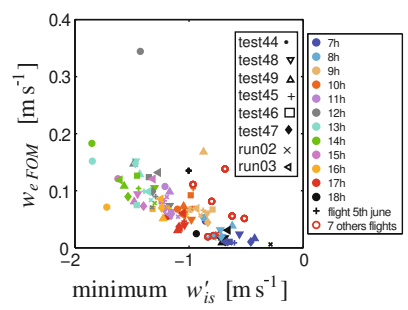

(c)

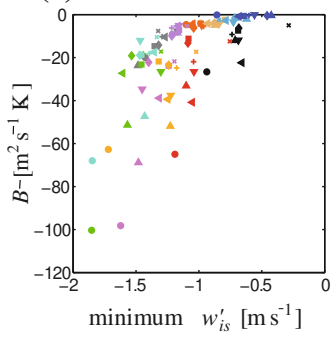

Fig. 12 Entrainment velocity versus a the minimum of $r_{\mathrm{v}}^{\prime}$ and $\mathbf{b}$ the minimum of $w^{\prime}$ in the dry intrusions. c Comparison between the minimum of the vertical velocity fluctuations and the area of negative buoyancy flux (see Fig. 1 for definition)

temperature and humidity profiles as the reference test but with different initial wind profiles leading to reduced shear. Note that $\beta$ is close to 0.1 between 0800 and 1100 UTC for all runs.

Figure 12 shows the relation between the observed negative fluctuations of water vapour mixing ratio and vertical velocity fluctuations inside the dry tongues with the entrainment velocity. Large entrainment velocities are associated with large fluctuations in $r_{\mathrm{v}}$ and $w$ inside the dry tongues. We must take into account the fact that the minimum of $w^{\prime}$ is located in the middle of the PBL and the minimum of $r_{\mathrm{v}}^{\prime}$ is located at the PBL top. The increase of $\left|w^{\prime}\right|$ from $Z_{i}$ to the middle of the PBL can be explained with decreasing positive buoyancy, favouring an increase in the descending motion. Couvreux et al. (2007) showed that the buoyancy of these structures could even become negative in the middle of the PBL, which substantially increases the descending motion toward the lower part of the PBL. These correlations between the entrainment rate and $r_{\mathrm{v}}^{\prime}$ can be explained by the fact that a large entrainment brings more dry air into the CBL and consequently the dry tongues are drier. This process favours a negative buoyancy and a negative vertical velocity in the dry tongues.

The area of negative buoyancy flux (denoted $B$-, see Fig. 1) is also an estimate of the entrainment of dry air into the PBL. Pino and Vilà-Guerau de Arellano (2008) compared several cases and showed larger negative areas for the case of sheared PBL than for pure buoyancy cases for a given $\beta$. Figure 12c compares this area with the minimum of $w^{\prime}$ in the dry tongues. The most intense negative fluctuations of $w$ are associated with the largest area 
of negative buoyancy flux. Note that this correlation, which leads to an increase in the amount of heat entrained from the free troposphere, is particularly obvious between 1100 and 1600 UTC, that is to say during the period of maximum PBL growth. The correlation between $w_{\mathrm{e}}$ and $B-$ is stronger than the correlation between $w_{\mathrm{e}}$ and $\beta$ (not shown here). This is to be expected since $B-$, like $w_{\mathrm{e}}$, is a driving parameter of the entrainment whereas $\beta$ is linked to $B-/ B+$, which also depends on the surface flux.

The sensitivity tests give different evolutions of the $B-$ area. Figure 12 also highlights the particular behaviour of tests 44 and 49, pointed out previously for their large entrainment velocity values, which here indicate stronger $w$ fluctuations in the dry tongues and a larger increase in $B$ - between 1100 and 1600 UTC than for the other cases. To sum up, these two tests show that the larger the shear stress and scalar jumps (not shown), the stronger the entrainment velocity and entrainment flux ratio. So the conclusions from various authors, summarized in Fedorovich and Conzemius (2008), are confirmed by our results.

\subsection{Evaluation of Entrainment Parametrization}

These parametrizations are frequently used for experimental studies or bulk models. In both cases, they are used to represent the closure of the entrainment heat flux. In experimental studies, the entrainment velocity parametrization provides estimations of fluxes of species for which direct measurement is not possible.

The complexity of the entrainment process makes it difficult to parametrize, even in models that allow the characteristics of the boundary layer and its interfaces to be resolved. Pino et al. (2003) determined in a zeroth-order-model case, a parametrization of $\beta$ depending on wind shear. Then Kim et al. (2003), Pino et al. (2006) and Conzemius and Fedorovich (2007) considered a first-order model to improve the entrainment parametrization. In our case, and as explained in Sect. 4, it is very important to consider a first-order model to explain the development of the boundary layer in the cases studied and consequently to include the entrainment zone in the parametrization of the entrainment processes. In this section, we evaluate the performance of some parametrizations of entrainment-zone thickness, entrainment rate and entrainment velocity based on a first-order model.

To solve the entrainment equations in a first-order model, the thickness of the entrainment zone $\delta$ must be calculated. Several authors (Kim et al. (2003), Sorbjan (2004), Conzemius and Fedorovich (2006b)) parameterized it by using the Richardson number:

$$
\frac{\delta}{Z_{i}}=b+\frac{a}{R_{i}}
$$

where $R_{i}=\frac{g}{\overline{\theta_{\mathrm{v}}}} \Delta \theta_{\mathrm{v}} \frac{Z_{i}}{v_{*}^{2}}$ and $v_{*}^{2}=w_{*}^{2}+4 u_{*}^{2}+0.1\left(\Delta U^{2}+\Delta V^{2}\right), u_{*}$ is the surface friction velocity, $w_{*}=\left(\frac{g}{\theta_{\mathrm{v}}} Z_{i} \overline{\left.w^{\prime} \theta_{\mathrm{v}}^{\prime}\right|_{0}}\right)^{1 / 3}$ is the convective velocity, $g$ is the acceleration due to gravity; $v_{*}^{2}$ is defined by Kim et al. (2006) and takes the wind shear across the inversion layer into account.

Figure 13 compares the parameterized entrainment-zone thickness calculated with Eq. 5 to that estimated directly from the LES flux profile (Fig. 1, method i). By using the same constants as in Pino et al. (2006), $a=1.12$ and $b=0.08$, we find that the proposed formulation is a satisfactory parametrization of the entrainment-zone thickness. Note that $\delta>600 \mathrm{~m}$ at midday for tests 44 and 49 due to larger wind shear at the PBL top. 
Fig. 13 Comparison of the depth of the entrainment zone calculated with the parametrization of Pino et al. (2006) and directly estimated with the buoyancy flux profile obtained by the LES. The coefficients $a$ and $b$ correspond to the coefficients used in Eq. 5 and $r$ is the correlation coefficient

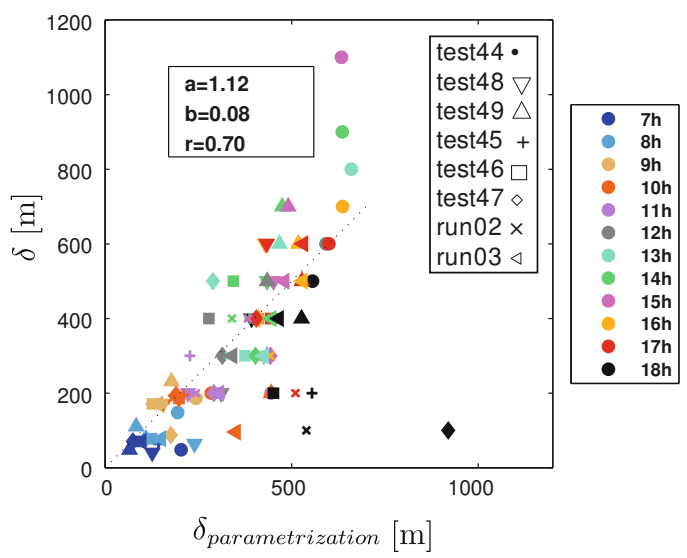

Pino et al. (2006), Kim et al. (2006) and Sun and Xu (2009) proposed to improve the $\beta$ parametrization (Eq. 1) by including the shear-stress contribution:

$$
\begin{aligned}
& \beta_{\mathrm{FOM}}=\left[1-\frac{\overline{\theta_{\mathrm{v}}} \Delta U^{2}}{2 g\left(\Delta \theta_{\mathrm{v}}-0.5 \gamma_{\theta} \delta\right)\left(Z_{i}+\delta\right)} A_{3}\right]^{-1} \\
& \times\left(A_{1} \frac{1}{1+\frac{\delta}{Z_{i}}}+A_{2}\left(\frac{u_{*}}{v_{*}}\right)^{3}+A_{3} \frac{\delta}{4 Z_{i}+2 \delta}\left[\frac{u_{*}^{2} \Delta U}{w_{*}^{\prime 3}}+\frac{\overline{\theta_{\mathrm{v}}} \Delta U^{2}}{g\left(Z_{i}+\delta\right)\left(\Delta \theta_{\mathrm{v}}-0.5 \gamma_{\theta} \delta\right)}\right]\right)
\end{aligned}
$$

where $A_{1}, A_{2}$ and $A_{3}$ are coefficients. This parametrization is based on the vertically-integrated turbulent kinetic energy budget in the sheared CBL. It takes account of the wind shear across the inversion layer (by using $\Delta U$ and $v_{*}$ ) and the shear in the surface layer (by using $u_{*}$ and $v_{*}$ ). The entrainment velocity used in the FOM model (Eq. 4) becomes (Kim et al. 2006; Sun and Yuan 2008):

$$
w_{\mathrm{FOM}}=\left.\frac{\partial Z_{i}}{\partial t}\right|_{\mathrm{FOM}}=-\left.\frac{\delta-\left(2 Z_{i}+\delta\right) \beta_{\mathrm{FOM}}}{Z_{i}\left(2 \Delta \theta_{v \mathrm{FOM}}-\gamma \delta\right)} \overline{w^{\prime} \theta_{\mathrm{v}}^{\prime}}\right|_{0},
$$

which is Eq. 4 rewritten to introduce $\beta_{\mathrm{FOM}}$.

We tested the coefficients $A_{1}$ to $A_{3}$ provided by Pino et al. (2006): $A_{1}=0.2$ is consistent with the classical closure value for a CBL with negligible shear and negligible depth of the entrainment zone, and $A_{2}=0.26$ agrees with the argument that most of the TKE produced at the surface dissipates locally. Kim et al. (2006) and Pino et al. (2006) used $A_{3}=1.44$ in this parametrization. This value implies that about $70 \%$ of the inversion-layer shear-produced TKE is available for the enhancement of entrainment. Conzemius and Fedorovich (2006b) and Sun and Yuan (2008) also suggest that the coefficient $A_{3}$ requires adjustment.

Figure 14 compares the parameterized values of $w_{\mathrm{e}}$ and $\beta$ in the LES to the values directly derived from the growth of the PBL $\partial Z_{i} / \partial t$ and from the flux profile respectively. The largest entrainment velocity values and also most entrainment rate values are overestimated by the parametrization, which shows that these parametrizations need to be improved in such Sahelian boundary layer. Figure 15a shows the same comparison as in Fig. 14b, with $A_{3}=1$. With this value, the parametrization gives slightly better results but it continues to overestimate the LES results. This value of $A_{3}$ implies that $50 \%$ of the inversion-layer shear-produced TKE is available for the enhancement of entrainment, rather than $70 \%$. Another test consists of evaluating the value of $A_{1}$. Figure $15 \mathrm{~b}$ shows a better fit in the comparison between the 

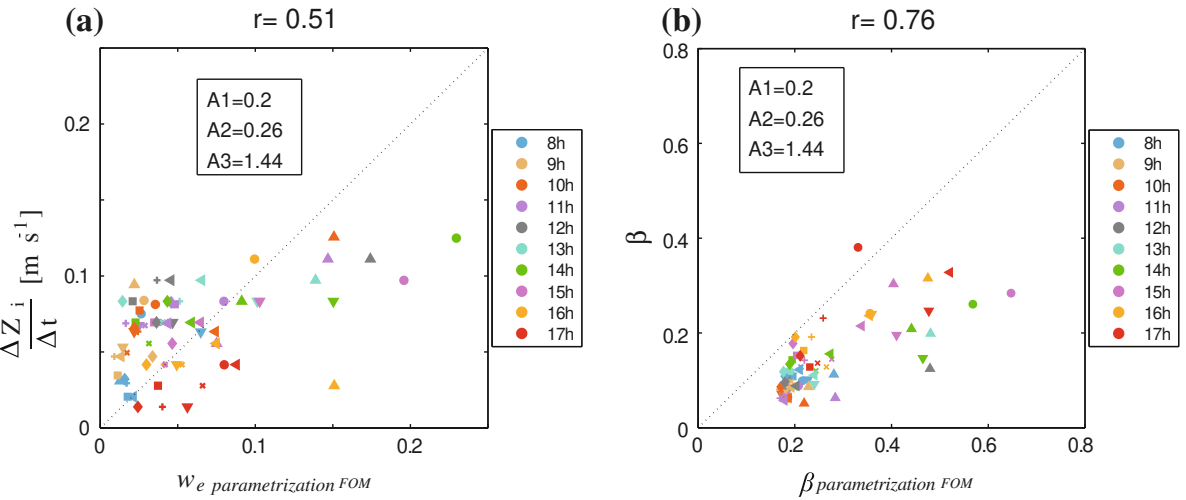

Fig. 14 Comparison between a the PBL growth rate and the parameterized entrainment velocity (Eq. 7) and b the parameterized entrainment rate (Eq. 6) and the entrainment rate, using $A_{3}=1.44$
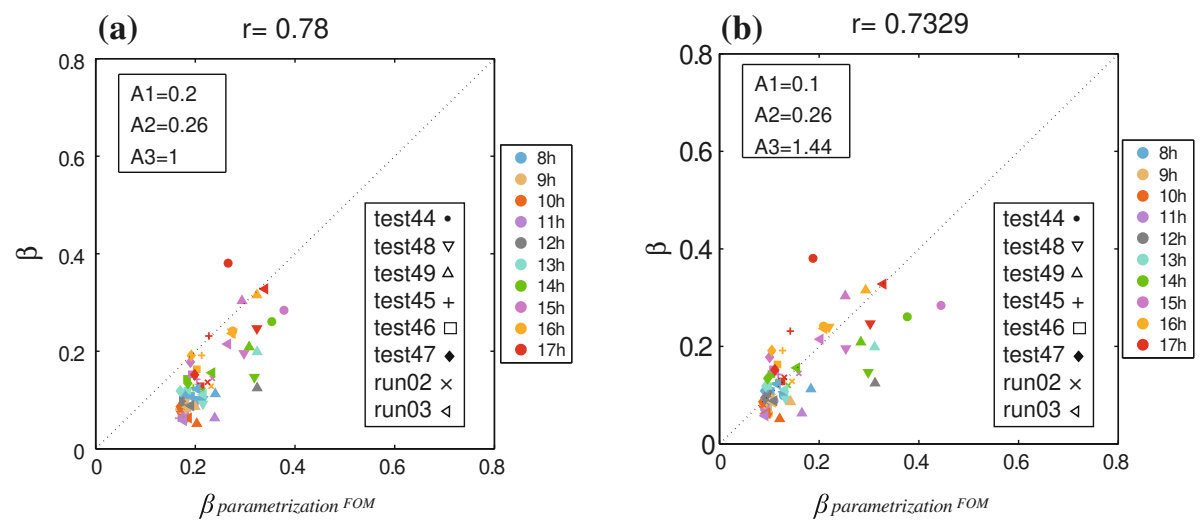

Fig. 15 Comparison between the parameterized entrainment rate and the entrainment rate obtained from the LES buoyancy flux profile, as in Fig. 14b, with a $A_{3}=1$ and $\mathbf{b} A_{1}=0.1$

parameterized values of $\beta$ in the LES with the values directly derived from the flux profile when $A_{1}=0.1$. This result confirms the non-universality of $\beta=0.2$ when $\delta$ is not equal to zero.

\section{Concluding Remarks}

Observations and numerical simulations have been used to better understand the role of the shear stress and the scalar jumps at the top of the mixed layer in the entrainment processes. The simulation of a real case (5 June 2006) provided a realistic picture of the PBL growth and of the coherent structures of entrainment even though stronger heat fluxes than those observed by aircraft had to be prescribed.

To be able to test the contribution of scalar jumps and wind shear to the entrainment, a series of sensitivity tests was carried out, covering a large range of conditions corresponding to those encountered during the transition period preceding the Monsoon season in West Africa. The thermodynamic and wind jumps at the PBL top vary from 1 to $3 \mathrm{~K}$ and -4 to 
$-7 \mathrm{~g} \mathrm{~kg}^{-1}$ and wind jumps vary from 0 to $13 \mathrm{~m} \mathrm{~s}^{-1}$. This sensitivity study allows a semi-arid environment test of several parametrizations of the entrainment velocity and entrainmentflux ratio used in the literature. An important result is the large range of entrainment rates encountered varying from 0.1 to 0.4 . This is similar to the range of values found with the aircraft observations in this region during the AMMA experiment.

Two assumptions (sharp discontinuity for the ZOM and finite depth for the FOM) made in mixed-layer models to describe the depth of the entrainment zone have been evaluated. The ZOM approach fails in the case studied because of large scalar jumps and deep inversion layers in the pre-monsoon Sahelian boundary layer. This should be particulary taken into account in semi-arid regions where the depth of the entrainment zone and the scalar jumps are often large.

Finally, the parametrization of the entrainment-layer depth based on the flux Richardson number frequently used in the literature is tested and satisfactorily represents the entrainment zone of the Sahelian sheared boundary layer. Additional parametrizations based on scaling arguments of the TKE budget and used in the recent literature in mixed-layer models are also tested. They perform satisfactorily regarding the entrainment velocity, provided a change is made in the constant coefficients. This highlights the role of the shear stress in the entrainment process and the necessity to take it into account correctly.

Acknowledgments The French authors are funded by Centre National de la Recherche Scientifique (CNRS), Université de Toulouse and Centre National de la Recherche Météorologique (CNRM). D. Pino's research was partially funded by the Spanish Ministry of Science and Innovation (MICINN, CGL2009-08609) and by the European project INTERREG FLUXPYR EFA 34/08. Based on a French initiative, AMMA was developed by an international scientific group and is currently funded by a large number of agencies, especially from France, UK, USA and Africa. It has been the beneficiary of a major financial contribution from the European Community's Sixth Framework Research Programme. Detailed information on scientific coordination and funding is available on the AMMA International web site http://www.amma-international.org. The aircraft was operated by the Service des Avions Francais Instrumenté pour la Recherche en Environnement (SAFIRE).

\section{References}

Agusti-Panareda A, Beljaars A, Ahlgrimm M, Balsamo G, Bock O, Forbes R, Ghelli F, Guichard A, Kohler M, Meynadier R, Morcrette JJ (2010) The ECMWF re-analysis for the AMMA observational campaign. Q J Roy Meteorol Soc 136:1457-1472

Angevine W (2008) Transitional, entraining, cloudy, and coastal boundary layers. Acta Geophys 56: 2-20. doi:10.2478/s11600-007-0035-1

Angevine WM, White AB, Avery SK (1994) Boundary-layer depth and entrainment zone characterization with a boundary-layer profiler. Boundary-Layer Meteorol 68:375-385

Canut G, Lothon M, Lohou F, Saïd F (2010) Observation of entrainment at the interface between monsoon flow and Saharan Air Layer. Q J Roy Meteorol Soc 136:34-46

Conzemius RJ, Fedorovich E (2006a) Dynamics of sheared convective boundary layer entrainment. Part I: methodology background and large-eddy simulations. J Atmos Sci 63:1151-1178

Conzemius RJ, Fedorovich E (2006b) Dynamics of sheared convective boundary layer entrainment. Part II: evaluation of bulk model predictions of entrainment flux. J Atmos Sci 63:1179-1199

Conzemius RJ, Fedorovich E (2007) Bulk models of the sheared convective boundary layer: evaluation through large eddy simulations. J Atmos Sci 64:786-807

Couvreux F, Guichard F, Redelsperger JL, Kiemle C, Masson V, Lafore JP, Flamant C (2005) Water-vapour variability within a convective boundary-layer assessed by large-eddy simulations and IHOP-2002 observations. Q J Roy Meteorol Soc 131:2665-2693

Couvreux F, Guichard F, Redelsperger JL, Masson V (2007) Negative water vapour skewness and dry tongues in the convective boundary layer: observations and LES budget analysis. Boundary-Layer Meteorol 123:269-294

Couvreux F, Guichard F, Bock O, Campistron B, Lafore J, Redelsperger JL (2010) Synoptic variability of the monsoon flux over west Africa prior to the onset. Q J Roy Meteorol Soc 136:169-173 
Cuxart J, Bougeault P, Redelsperger JL (2000) A turbulence scheme allowing for mesoscale and large-eddy simulations. Q J Roy Meteorol Soc 26:1-30

Driedonks AGM (1982) Models and observations of the growth of the atmospheric boundary layer. Boundary-Layer Meteorol 23:283-306

Faloona I, Lenschow DH, Stevens B, Campos T, Blomquist B, Thornton D, Bandy A, Gerber H, Van Zanten M (2005) Observations of entrainment in eastern Pacific marine stratocumulus using three conserved scalars. J Atmos Sci 62:3268-3285

Fedorovich E, Conzemius R (2008) Effects of wind shear on the atmospheric convective boundary-layer structure and evolution. Acta Geophys 56:114-141

Fedorovich E, Conzemius R, Mironov D (2004) Convective entrainment into a shear-free, linearly stratified atmosphere: bulk models reevaluated through large eddy simulations. J Atmos Sci 61:281-295

Garratt JR (1992) The atmospheric boundary layer. Cambridge University Press, Cambridge, 316 pp

Grossman RL, Nimal G (1995) Moisture flux and mixing processes in the daytime continental convective boundary layer. J Geophys Res 100:25665-25674

Gryning SE, Batcharova E (1990) Analytical model for the growth of the coastal internal boundary layer during onshore flow. Q J Roy Meteorol Soc 116:187-203

Kalapureddy M, Lothon M, Campistron B, Lohou F, Saïd F (2010) Wind profiler analysis of the African Easterly Jet in relation with the boundary layer and the Saharan Heat-Low. Q J Roy Meteorol Soc 136:141-158

Kawa SR, Pearson J (1989) An observational study of stratocumulus entrainment and thermodynamics. J Atmos Sci 46:2649-2661

Kim S, Park S, Moeng CH (2003) Entrainment processes in the convective boundary layer with varying wind shear. Boundary-Layer Meteorol 108:221-245

Kim SW, Park SU, Pino D, Vilà-Gueraude Arellano J (2006) Parameterization of entrainment in a sheared convective boundary layer using a first-order jump model. Boundary-Layer Meteorol 120:445-475

Lafore JP, Stein J, Asencio N, Bougeault P, Ducrocq V, Duron J, Fischer C, Héreil P, Mascart P, Redelsperger JL, Richard E, Vilà-Guerau de Arellano J (1998) The Meso-NH atmospheric simulation system. Part I: adiabatic formulation and control simulations. Ann Geophys 109:16-90

Lebel T, Parker DJ, Flamant C, Bourlès B, Marticorena B, Mougin C, Peugeot E, Diedhiou A, Haywood JM, Ngamini JB, Polcher J, Redelsperger JL, Thorncroft CD (2010) The AMMA field campaigns: multiscale and multidisciplinary observations in the West African region. Q J Roy Meteorol Soc 136:8-33

Lenschow DH, Krummel PB, Siems ST (1999) Measuring entrainment, divergence and vorticity on the mesoscale from aircraft. J Atmos Ocean Technol 16:1384-1400

Lilly DK (1968) Models of cloudy-topped mixed layers under a strong inversion. Q J Roy Meteorol Soc 94:292-309

Lohou F, Saïd F, Lothon M, Durand P, Serça D (2010) Impact of the boundary-layer processes on surface turbulence characteristics in the frame of the west african monsoon. Boundary-Layer Meteorol 136:1-23

Lothon M, Couvreux F, Donier S, Guichard F, Lacarrère P, Noilhan J, Saïd F (2007) Impact of the coherent eddies on airborne measurements of vertical turbulent fluxes. Boundary-Layer Meteorol. 124

Lothon M, Saï F, Lohou F, Campistron B (2008) Observation of the diurnal cycle in the low troposphere of West Africa. Mon Weather Rev 136

Mahrt L. (1991) Boundary-layer moisture regimes. Q J Roy Meteorol Soc 117:151-176

Pino D, Vilà-Guerau de Arellano J (2008) Effects of shear in the convective boundary layer: analysis of the turbulent kinetic energy budget. Acta Geophys 56:167-193

Pino D, Vilà-Guerau de Arellano J, Duynkerke PG (2003) The contribution of shear to the evolution of a convective boundary layer. J Atmos Sci 60:1913-1926

Pino D, Vilà-Gueraude Arellano J, Kim S-W (2006) Representing sheared convective boundary layer zero- and first-order-jump mixed-layer models: Large-eddy simulation verification. J Appl Meterol Clim 45:12241243

Redelsperger JL, Sommeria G (1982) Method of representing the turbulence at scales inferior to the grid in a three-dimensional model of cloud convecion. Boundary-Layer Meteorol 21:509-530

Saïd F, Canut G, Durand M, Lothon P, Lohou F (2010) Seasonal evolution of boundary-layer turbulence measured by aircraft during the AMMA 2006 special observation period. Q J Roy Meteorol Soc 136:47-65

Sorbjan Z (1996) Effects caused by varying the strength of the capping inversion based on a large eddy simulation model of the shear-free convective boundary layer. J Atmos Sci 53:2015-2024

Sorbjan Z (2004) Large-eddy simulations of the baroclinic mixed layer. Boundary-Layer Meteorol 112:57-80

Stull RB (1976) The energetics of entrainment across a density interface. J Atmos Sci 33:1260-1267

Stull RB (1988) An introduction to boundary layer meteorology, new edition, 1999. Kluwer, Dordrecht, 666 pp 
Sullivan PP, Moeng C-H, Stevens B, Lenschow DH, Mayor SD (1998) Structure of the entrainment zone capping the convective atmospheric boundary layer. Q J Roy Meteorol Soc 55:3042-3064

Sun J, Xu Q (2009) Parameterization of sheared convective entrainment in the first-order jump model: evaluation through large-eddy simulation. Boundary-Layer Meteorol 132:279-288

Sun J, Yuan W (2008) Effect of the entrainment flux ratio on the relationship between entrainment rate and convective Richardson number. Boundary-Layer Meteorol 126:237-247

Tennekes H (1973) A model for the dynamics of the inversion above a convective boundary layer. J Atmos Sci 30:538-567

Tennekes H, Driedonks AGM (1981) Basic entrainment equations for the atmospheric boundary layer. Boundary-Layer Meteorol 20: 515-531. doi:10.1007/BF00122299

Turner D, Wagner E, Wulfmeyer V, Pal S, Larry K (2010) Raman lidar observations of water vapor mixing ratio turbulence profiles in the convective boundary layer. Oral presentation, International symposium for the advanced of boundary layer remote sensing, 28-30 June 2010, Paris

Van Zanten MC, Duynkerke P, Cuijpers J (1999) Entrainment parameterization in convective boundary layers. J Atmos Sci 56:813-828 